\title{
Nonunion of Medial Malleolus Fracture: Tension Band Wiring is an Effective Option Even in Failed Surgeries
}

\author{
Dilip D Tanna ${ }^{1}$, Prasoon Kumar², Mandeep S Dhillon ${ }^{3}$
}

\begin{abstract}
Nonunions of medial malleolus (MM) are a relatively rare entity, especially after previous surgical stabilization. These are routinely managed with compression screws and autografts. Usage of tension band wiring (TBW) is very common in acute MM fractures; however, its usefulness in nonunion scenarios has been sporadically reported. We treated a 7-year-old MM nonunion with TBW, which united well after 5 months of follow-up. We present this technique highlighting its critical steps and additionally review previous cases that were treated similarly with good outcomes. Keywords: Autograft, Medial malleolus, Neglected ankle, Nonunion, Tension band, Tension band wiring. Journal of Foot and Ankle Surgery (Asia Pacific) (2019): 10.5005/jp-journals-10040-1111
\end{abstract}

\section{BACKGROUND}

Nonunions in medial malleolus (MM) fractures are a rare though disabling scenario, with variable reports citing an incidence from 5 to $30 \%$, with long-term complications related to the ankle joint. ${ }^{1,2}$ This problem has become even rarer with the advent of routine operative management with anatomical reduction and fixation. ${ }^{3,4}$ Surgery is indicated for symptomatic nonunions causing significant pain, inflammation, and instability. ${ }^{1,5}$

The most cited surgical technique involves screw fixation with bone substitutes. ${ }^{1,3}$ In our practice, we prefer tension band wiring with autograft for atrophic nonunion of the MM, since it is a biomechanically stronger construct with more stiffness, and provides better compression. ${ }^{6}$ Additionally, the compression screw can damage the inlaid graft, and in fractures where the distal fragment is very small, the use of screw becomes impractical. We highlight the critical steps of this surgery performed by the principal author (DDT) in a 7-year-old case of nonunion and have added a literature review of similar surgeries from the literature.

\section{Preoperative Assessment}

Standard plain radiographs and computed tomography (CT) scans are taken to assess the fracture type and gap. MRI may be used to evaluate associated ligament injuries and the existence of any infection. Blood investigations like ESR, leukocyte counts, and C-reactive proteins help in diagnosing infection as a cause of nonunion.

\section{Case Description}

The patient suffered the injury about 7 years prior to presentation and was treated with TBW for right MM fracture (Fig. 1). 1 year after the index surgery, the wires were removed because of their prominence causing discomfort to the patient. After 5 years the patient revisited the outpatient department, due to pain, where X-rays and MRI were labeled "normal," and the patient was informed that he had no significant problem (Figs 2 and 3). He carried on with reasonable function but with some discomfort in the ankle for another 2 years, after which due to persistent symptoms, plain radiographs, and $C T$ scans were repeated; these demonstrated nonunion of the MM, which was now 7 years old (Figs 4 to 6).
${ }^{1}$ Department of Orthopaedics, Tanna Hospital, Mumbai, Maharashtra, India

${ }^{2,3}$ Department of Orthopaedics, Postgraduate Institute of Medical Education and Research, Chandigarh, India

Corresponding Author: Prasoon Kumar, Department of Orthopaedics, Postgraduate Institute of Medical Education and Research, Chandigarh, India, Phone: +91 9781002142, e-mail: drprasoonksingh@gmail.com

How to cite this article: Tanna DD, Kumar P, Dhillon MS. Nonunion of Medial Malleolus Fracture: Tension Band Wiring is an Effective Option Even in Failed Surgeries. J Foot Ankle Surg (Asia Pacific) 2019;6(2): $52-56$.

Source of support: Nil

Conflict of interest: None

Surgery was planned for this case, and despite a failure of previous TBW, the same procedure with the addition of autograft was contemplated.

\section{Surgical Technique}

Anesthesia

Regional spinal-epidural anesthesia was used.

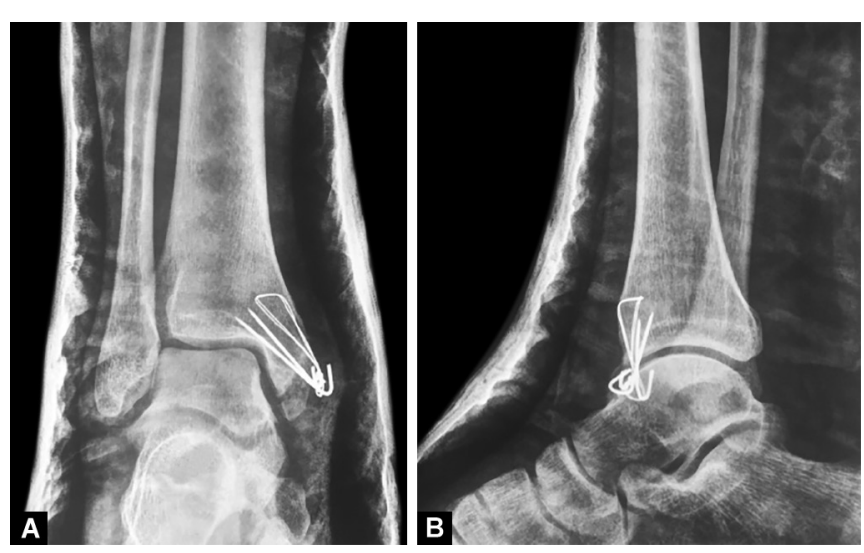

Figs $1 \mathrm{~A}$ and $\mathrm{B}$ : Postoperative plain radiographs after the index surgery

(0) The Author(s). 2019 Open Access This article is distributed under the terms of the Creative Commons Attribution 4.0 International License (https://creativecommons. org/licenses/by-nc/4.0/), which permits unrestricted use, distribution, and non-commercial reproduction in any medium, provided you give appropriate credit to the original author(s) and the source, provide a link to the Creative Commons license, and indicate if changes were made. The Creative Commons Public Domain Dedication waiver (http://creativecommons.org/publicdomain/zero/1.0/) applies to the data made available in this article, unless otherwise stated. 


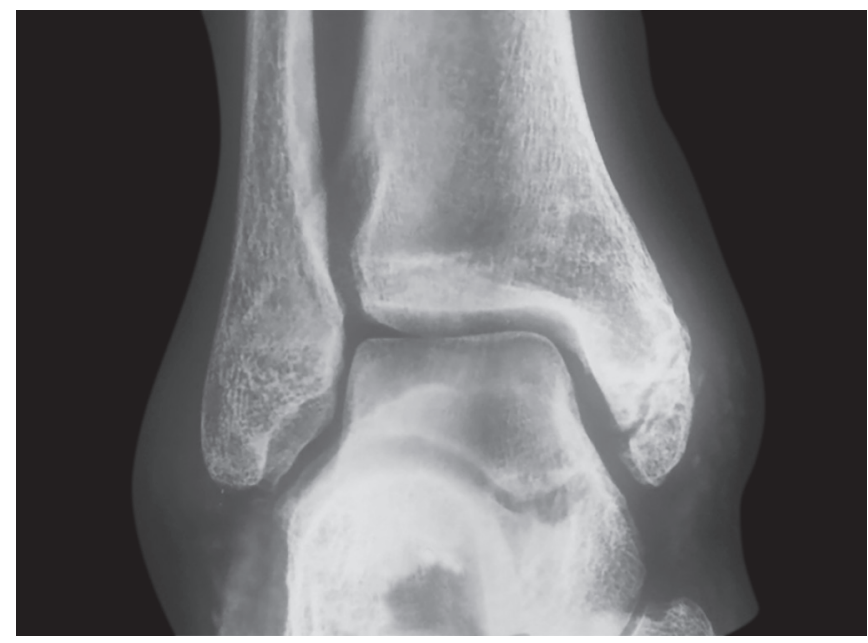

Fig. 2: X-rays at 5 years of follow-up

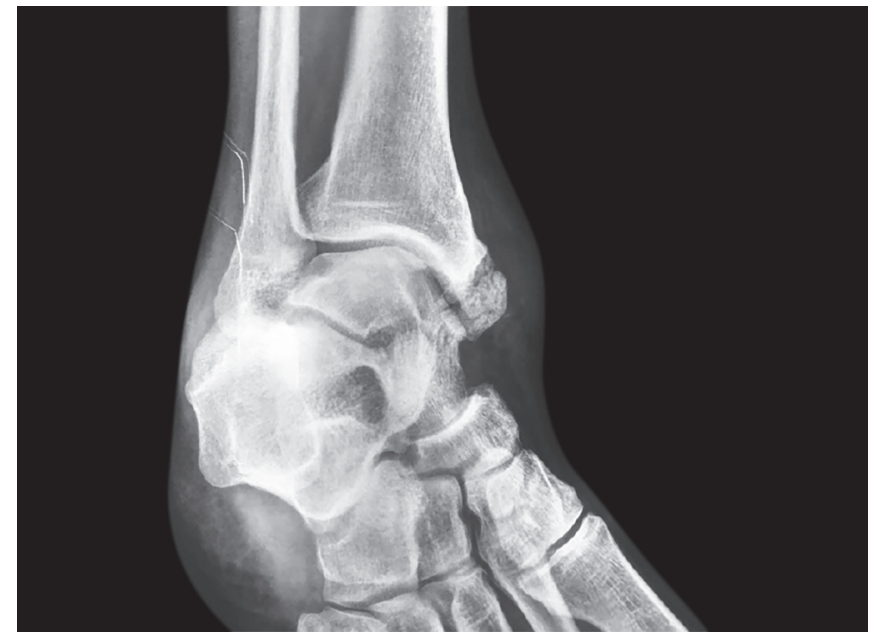

Fig. 4: X-ray at 7 years of follow-up showing the nonunion

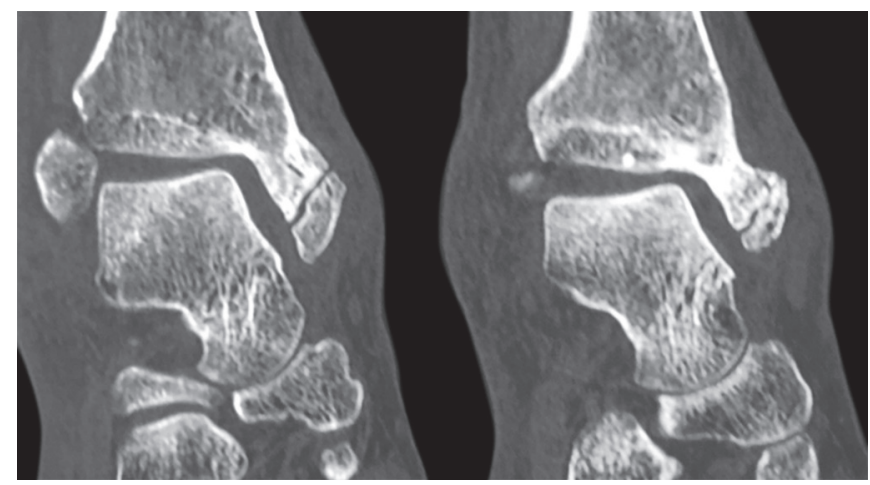

Fig. 6: Plain CT scan showing gap nonunion

\section{Position of the Patient}

The surgery was done in supine position with the affected limb in $45-60^{\circ}$ of flexion at the knee and the hip abducted and externally rotated, forming a figure of " 4 " position. Alternatively, surgery can be done in an ipsilateral lateral decubitus with the side to be operated at the bottom. The normal leg can be flexed at the knee to facilitate the

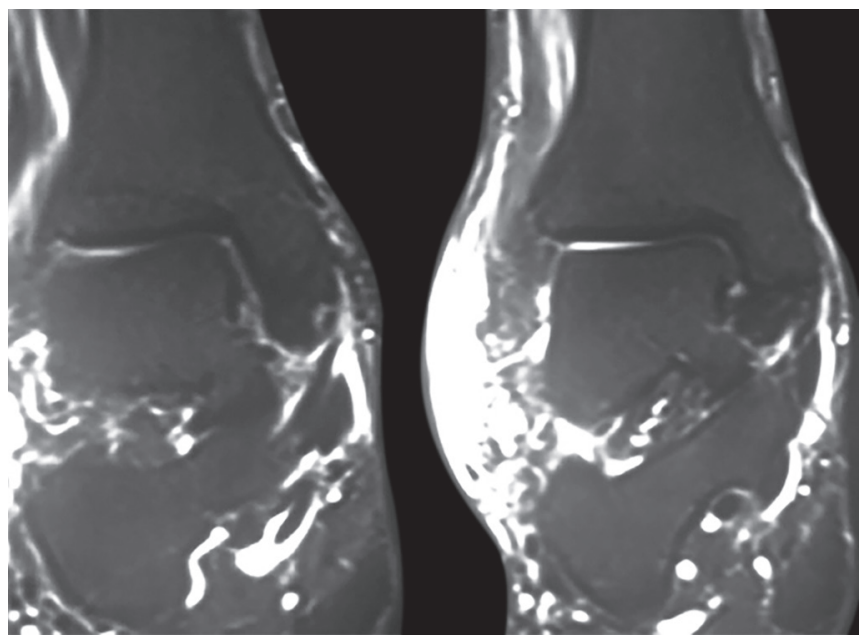

Fig. 3: Inconspicuous MRI at 5 years of follow-up

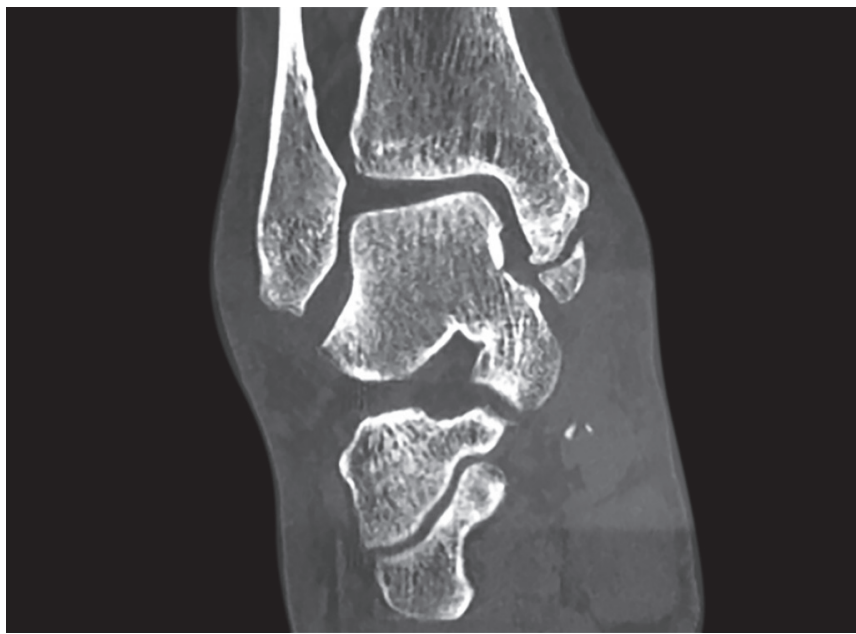

Fig. 5: Plain CT scan showing gap nonunion

intraoperative C-arm imaging. A small radiolucent sandbag or bolster can be placed underneath the ankle as per the surgeon's preference.

\section{Incision}

The standard medial approach was used, centered at the MM, and the incision was anteriorly curved distally.

\section{Critical Steps}

The fragment was identified, and the fracture site exposed (Figs 7 to 9). The fracture site was cleared of debris, including periosteal remnants, fibrous tissue, etc. The fracture ends were freshened with a high-speed burr until punctate bleeding was observed (Fig. 10). This creates a gap that is eventually filled with an inlay tricortical autograft from the iliac crest (Fig. 11). Weber's reduction clamp was used to reduce the fracture with the inlaid graft, which was smoothened with the burr, and 2-3 K wires of $2-2.5 \mathrm{~mm}$ were inserted into this bone-graft-bone assembly (Fig. 12). A $3.5 \mathrm{~mm}$ partially threaded cancellous screw was inserted at the metaphysis parallel to the plafond. Tension band wiring with 18 French stainless steel wire was done using the standard method with the proximal loop of the " 8 " turned around the cancellous screw head, which was then tightened to hold the wire (Fig. 13). 


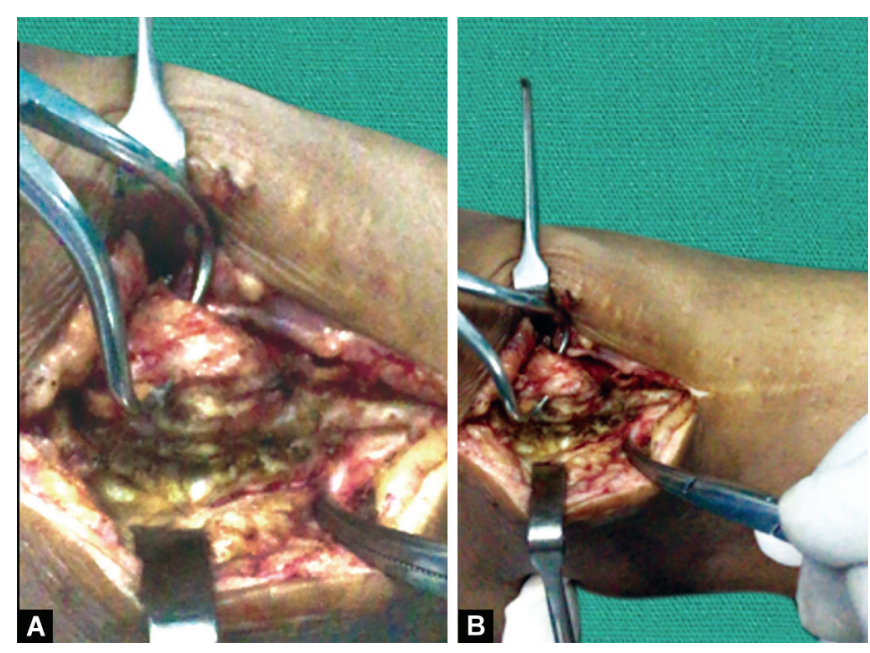

Figs 7A and B: Intraoperative identification and clamping of the fragment

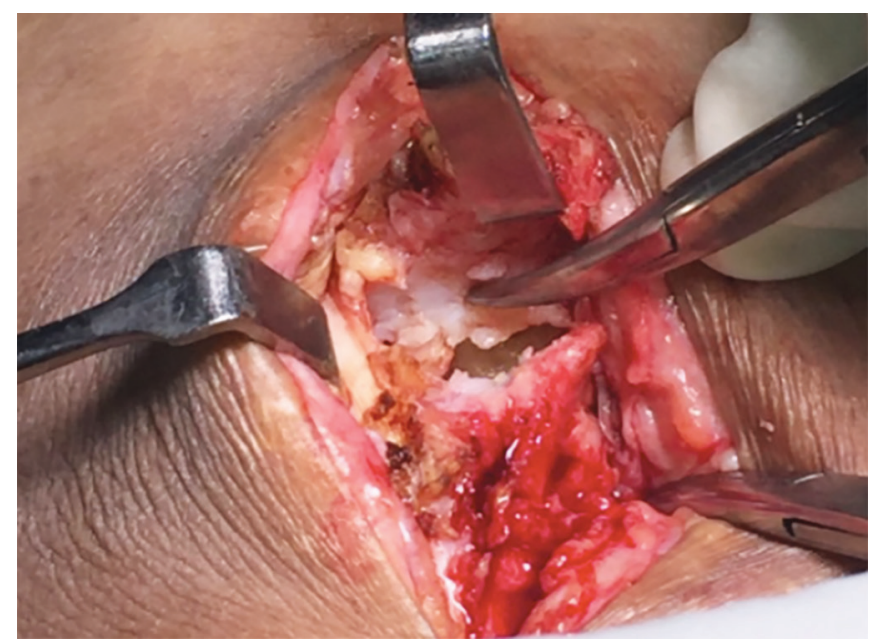

Fig. 9: Photograph showing the actual gap at the nonunion site
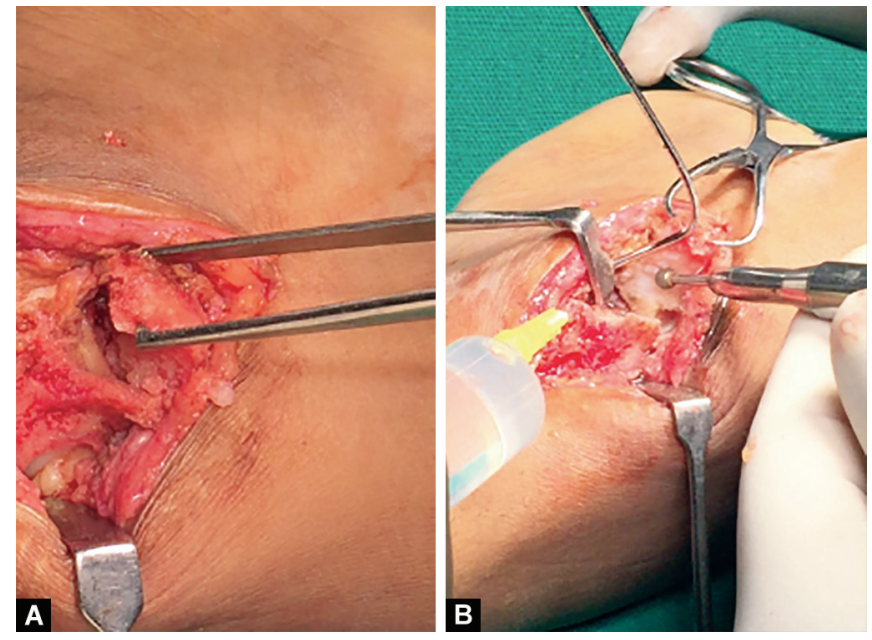

Figs $11 \mathrm{~A}$ and $\mathrm{B}$ : Photograph depicting inlay bone grafting and its smoothening with burr

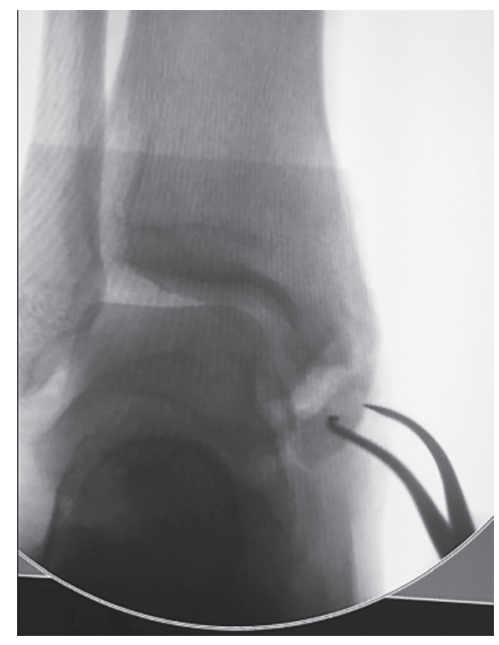

Fig. 8: Intraoperative identification and clamping of the fragment

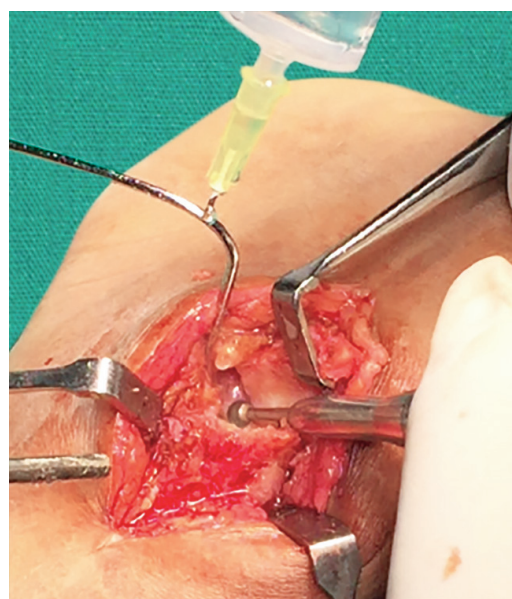

Fig. 10: Photograph showing usage of high-speed burr to freshen the fracture ends
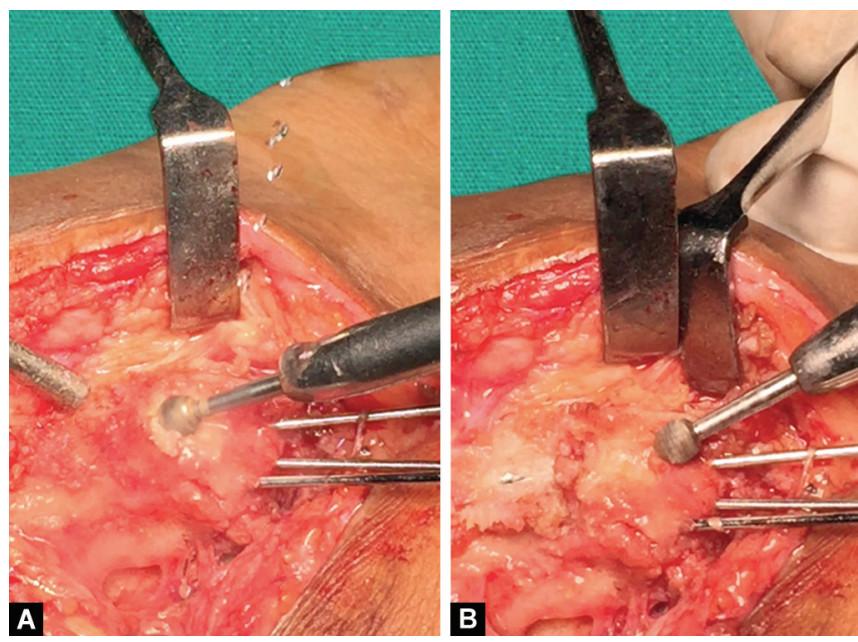

Figs $12 \mathrm{~A}$ and $\mathrm{B}$ : Photograph depicting inlay bone grafting and its smoothening with burr 


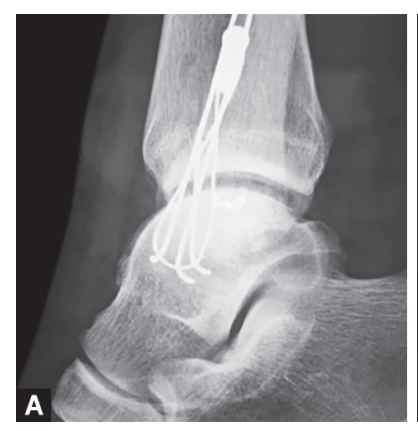

Figs $13 \mathrm{~A}$ and $\mathrm{B}$ : Postoperative $\mathrm{X}$-ray

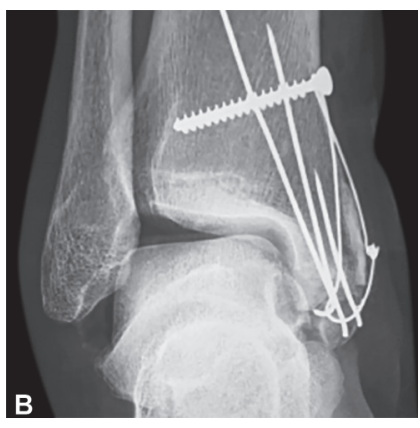

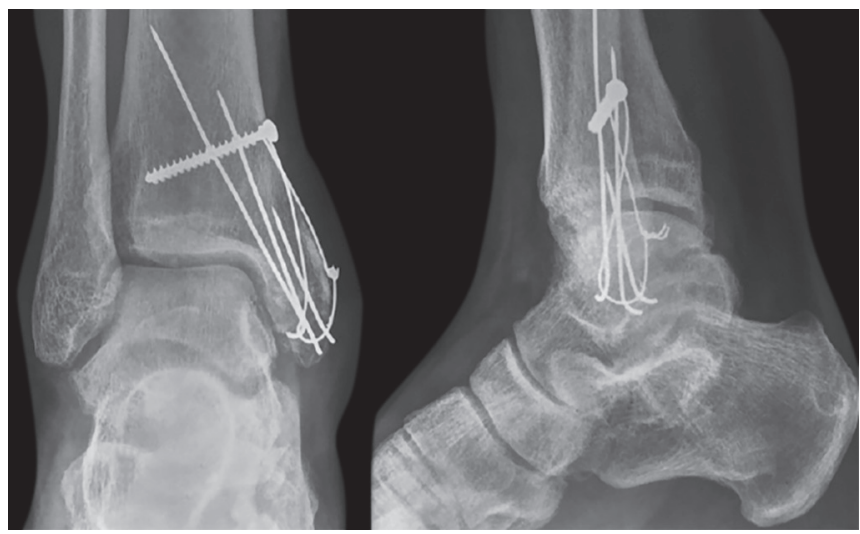

Fig. 14: X-rays showing complete union at 5 months follow-up
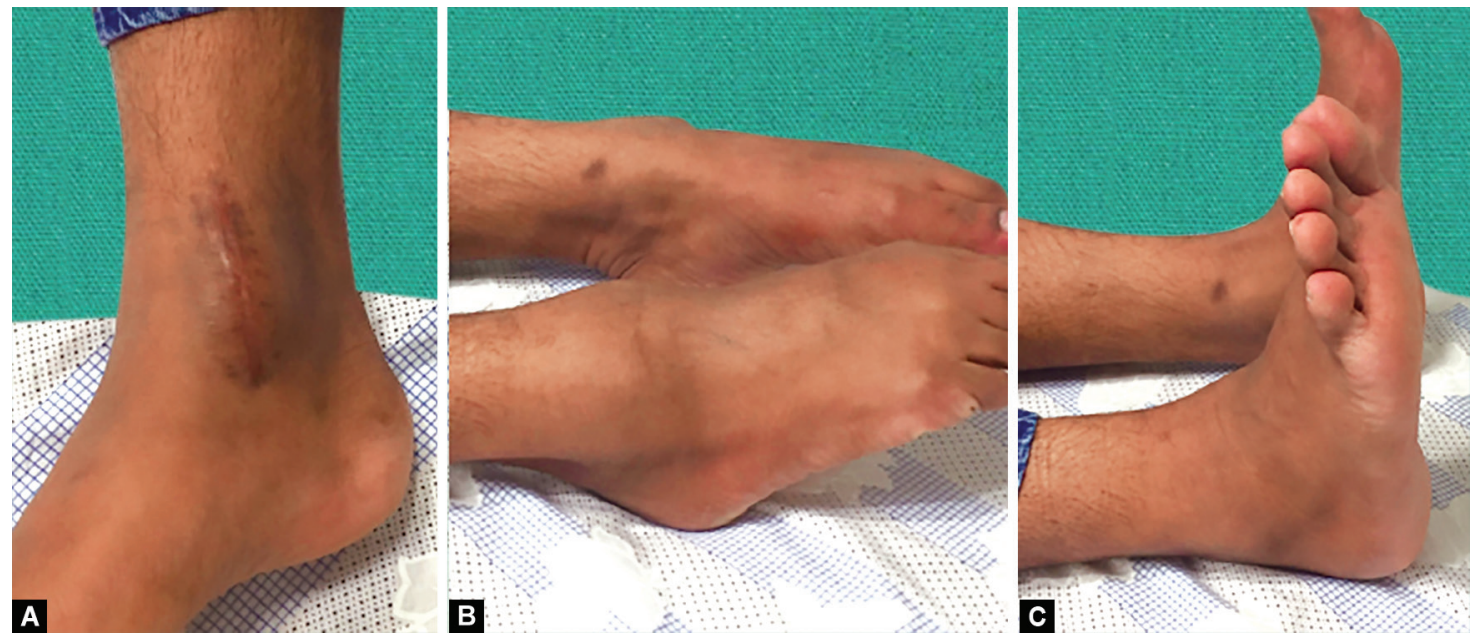

Figs $15 \mathrm{~A}$ to $\mathrm{C}$ : Photographs showing healed scar excellent function at the ankle joint

\section{Postoperative Care}

The ankle was immobilized in a below-knee slab for 4 weeks, followed by gradual ankle range of motion (ROM) exercises. Patient was kept non-weight-bearing for 4 weeks, and then partial weight bearing in a protective boot until the union occurred by 5 months (Fig. 14). With an adequate rehabilitation protocol, we were able to achieve good functional outcomes in our patients (Fig. 15).

\section{Discussion}

Conventionally, compression screws have been described as the treatment of choice for nonunions of the MM. Madhu et al. successfully operated three cases with screws and graft that united well at 4 months. ${ }^{3}$ Similarly, Khurana et al. operated one case with compression screw and iliac crest aspirate and reported good outcome. ${ }^{4}$ However, the disadvantages in terms of chances of graft breakage with a screw, along with difficulty in purchase when the fragment is small, makes TBW an effective alternative.

Nonunion of MM after prior fixation is extremely rare. ${ }^{1,4} \mathrm{~A}$ PubMed search on 26.7.2019 with keywords; non[All Fields] AND union[All Fields] AND medial[All Fields] AND malleolus[All Fields] yielded only 21 hits out of which only two studies reported on these fractures treated with TBW.
Kanakis et al. reported $100 \%$ rates of union in seven patients with pseudoarthrosis of the MM, treated with TBW. ${ }^{7}$ The average period between injury and surgery for these cases was 5 months. None of these patients were previously operated. On a functional score evaluated on the basis of pain, walk, stability, and radiographic findings of arthritis, six of these cases had excellent outcomes. One remaining case also had a good outcome.

John et al. reported a neglected case of 6 months old MM fracture treated by TBW and inlay autograft, similar to our technique, that showed no signs of osteoarthritis at 3 years of follow-up ${ }^{1}$ (Table 1). The authors concluded that TBW may be a better option when compared to screw fixation as it requires a simple technique, is cheaper, can provide controlled compression with the tension band principle, protects the graft from damage and can be utilized even if the bone quality is poor that could lead to suboptimal hold of the screw. ${ }^{1}$

The important point from both these cases is that neither of them was operated as a fresh fracture, however, in the present case, the index surgery with TBW failed and had a delayed diagnosis of nonunion after 7 years. This adds to the novelty of the present case. The conventional method employed for such a failure is a compression screw, and the old adage that if one procedure fails, 
Table 1: Review of literature for tension band wiring usage in nonunion of medial malleolus

\begin{tabular}{llllll}
\hline Author & Year & No. of cases & Surgical technique & Follow-up & Outcome \\
\hline John et al. $^{1}$ & 2017 & 1 & $\begin{array}{l}\text { TBW + iliac crest inlay } \\
\text { graft }\end{array}$ & 3 years & $\begin{array}{l}\text { No secondary osteoarthritis, } \\
\text { ROM (DF } 15^{\circ} \text { and PF } 45^{\circ} \text { ) }\end{array}$ \\
Kanakis et al. $^{7}$ & 1990 & 7 & $\begin{array}{l}\text { TBW (grafts usage not } \\
\text { specified) }\end{array}$ & $\begin{array}{l}3.5 \text { years (mean) } \\
\text { Six patients had excellent } \\
\text { outcomes; one patient had } \\
\text { good outcome }\end{array}$ \\
$\begin{array}{l}\text { Tanna et al. } \\
\text { (present case) }\end{array}$ & 2019 & 1 & $\begin{array}{l}\text { TBW + iliac crest inlay } \\
\text { graft }\end{array}$ & 6 months & United at 5 months \\
\hline
\end{tabular}

TBW, tension band wiring; ROM, range of motion; DF, dorsiflexion; PF, plantar flexion

then it should not be repeated for the same fracture is universally utilized. However, the time-tested procedure of TBW is easy, costeffective, and can be used for small fragments also.

\section{CONCLUSION}

Tension band wiring is an effective surgical technique for nonunions of MM even after previous surgery. It is easy to use, and most of the surgeons are well acquainted with the technique; it protects the inlaid graft and can even be used in fractures with comminution and in osteoporotic bones.

\section{References}

1. John R, Dhillon MS, Khurana A, et al. Tension band wiring is as effective as a compression screw in a neglected, medial maleolus non-union: a case-based discussion \& literature review. J Orthop Case Rep 2017;7(4):72-75. DOI: 10.13107/jocr.2250-0685.860.
2. Mindell ER, Rogers 3rd WJ. Refracture of ununited medial malleolus. Clin Orthop 1958;11:233-236.

3. Madhu T, Morgan-Jones R. A modified operative technique for enhanced compression of medial malleolar non-union. Injury Extra 2005;36:520-525.

4. Khurana S, Karia R, Egol KA. Operative treatment of nonunion following distal fibula and medial malleolar ankle fractures. Foot Ankle Int 2013;34(3):365-371. DOI: 10.1177/1071100712473740.

5. Banks SW. The treatment of non-union of fractures of the medial malleolus. J Bone Joint Surg Am 1949;31A(3):658-662.

6. Ostrum RF, Litsky AS. Tension band fixation of medial malleolus fractures. J Orthop Trauma 1992;6(4):464-468. DOI: 10.1097/00005131199212000-00013.

7. Kanakis TE, Papadakis E, Orfanos A, et al. Figure eight tension band in the treatment of fractures and pseudarthroses of the medial malleolus. Injury 1990;21(6):393-397. DOI: 10.1016/00201383(90)90128-h. 